\title{
A CIDADE, O TEMPO E A EXPERIÊNCIA DE UM MUSEU VIRTUAL: PESQUISA ANTROPOCRONOTOPOLÓGICA NAS NOVAS TECNOLOGIAS ${ }^{1}$
}

\author{
Ana Luiza Carvalho da Rocha e \\ Cornelia Eckert Núcleo de Antropologia Visual e Banco de \\ Imagem e Efeitos Visuais, Laboratório de Antropologia
}

Social, PPGAS, UFRGS.

Le destin, comme l'espace, est du coté du 'figuratif', de l'image.

Il tourne le dos à l'angoisse sans figure de la fuite du temps.

(G. Durand, Science de l'homme et radition, 1979)

\section{Introdução}

Esta apresentação é, para nós, uma primeira tentativa de sistematizar inúmeras reflexões, ainda que incipientes, acerca da inserção, em página WEB, da produção de documentos etnográficos antigos e recentes sobre as transformações na paisagem urbana de Porto Alegre inventariados no Banco de Imagens e Efeitos Visuais, projeto por nós coordenado.

A pesquisa com as novas redes eletrônicas e digitais orientada para a criação de um site para o Banco de Imagens e Efeitos Visuais terá por endereço www.itineráriosportoalegre.ufrgs.br . O desenvolvimento desse projeto só tem sido possível graças à parceria e à orientação do Prof. Luiz Antônio Rocha, do Departamento de Artes da UFRGS.

Problematiza-se, assim, o tratamento documental de coleções etnográficas no processo de patrimonialização do mundo urbano contemporâneo, tendo como foco o uso de novas tecnologias digitais e eletrônicas.

Trata-se do desenvolvimento do Projeto Integrado Estudo antropológico de itinerários urbanos, memória coletiva e formas de sociabilidade no mundo urbano contemporâneo, que vem sendo realizado junto ao Núcleo de Pesquisa sobre Culturas Contemporâneas do Programa de Pós-Graduação em Antropologia Social/UFRGS.

\footnotetext{
1 Texto apresentado na XXII Reunião Brasileira de Antropologia no Fórum Especial Os Museus Etnográficos no contexto da antropologia contemporânea, em Brasília, de 16 a 19 de julho 2000, sob o título "Relato de uma experiência de criação de um museu virtual na área de Antropologia Urbana".
} 
O referido Projeto Integrado reúne os dados de pesquisa dos projetos individuais Antropologia do cotidiano e estudos das sociabilidades a partir das feições dos medos e das crises na vida metropolitana e Coleções etnográficas, itinerários urbanos e patrimônio etnológico: a criação de um Museu Virtual de Porto Alegre e tem como núcleo comum o estudo do caráter temporal da experiência humana presente ao mundo contemporâneo e as suas repercussões nas práticas e saberes que os indivíduos e/ou grupos urbanos constroem em suas relações com a cidade.

Esse experimento ocupa, no referido projeto, um dos lugares por nós destinados para a construção do texto etnográfico, além dos recursos fotográficos e videográficos que vimos utilizando até o momento no tratamento documental do percurso de patrimonialização no mundo citadino local.

Considerando-se, portanto, alguns esquemas enunciativos da Antropologia Urbana e da Antropologia Visual, o projeto de criação de um Museu Virtual pretende disponibilizar aos usuários das redes eletrônicas e digitais, as relações entre os acontecimentos ou incidentes vividos por grupos e/ou indivíduos em Porto Alegre e a memória monumental da cidade, na tentativa de investir na presença de comunidades interpretativas $^{2}$ no que se refere à apropriação das representações e das práticas sociais referidas ao patrimônio etnológico local.

\section{A cidade como objeto temporal: idéias para criação da arquitetura do site}

Como sugere cada vez mais a análise compreensiva dos fenômenos da memória e do patrimônio no mundo contemporâneo que vimos desenvolvendo, o tempo torna-se humano na medida em que está articulado de forma narrativa e em que as ações, as situações e os acontecimento vividos esboçam traços da experiência temporal humana ${ }^{3}$.

Desse modo, ao usar tecnologias da informática com o tratamento eletrônico ou digital da memória, problematizamos a noção do tempo como realidade composta de um continuum de instantes logicamente hierarquizados e não como "monumentos de lembranças". Nesse sentido, propomos que os jogos de simulação permitem a criação de formas mais integrativas e interativas de resgate, recuperação, criação e produção de

\footnotetext{
${ }^{2}$ Essa expressão é utilizada aqui no sentido crítico a ela atribuído por P. RABINOW, Antropologia da Razão, Rio de Janeiro, Relume-Dumará, 1999, pp.92-98, isto é, ao se considerar, na produção do texto etnográfico experimental pela via das novas tecnologias, as relações que ele possibilita entre as formas representacionais da memória e patrimônio e as práticas sociais locais. Nesse sentido, o autor nos alerta, citando Weber, que o processo de "museologização" do mundo tende a ignorar o perigo de obliteração das diferenças dos significados culturais disponíveis social e historicamente, acabando por confundir a experiência e o sentido no tratamento da dimensão formal da representação.

${ }^{3}$ Cf. Paul RICOEUR, Tempo e Narrativa, São Paulo, Papirus, 1994, Vol. II.
} 
coleções etnográficas.

Tomando-se a Cidade como obra que diz respeito à criação coletiva, baseada no comportamento estético ${ }^{4}$ de uma comunidade de destino, a pesquisa em torno de movos experimentos etnográficos com base nas tecnologias digitais e eletrônicas tem nos permitido explorar melhor os critérios de pertinência do uso do pormenor ou do fragmento ${ }^{5}$ como fonte descritiva dos jogos da memória de seus habitantes.

A concepção da arquitetura do site tem se constituído na expectativa da leitura/interpretação do objeto-cidade pelo usuário do site no sentido de confrontá-lo com dois tipos de divisibilidade das imagens dos fenômenos urbanos, no espaço e no tempo: o corte e a ruptura. Neste ponto, corte e ruptura têm sido tomados aqui como elementos indutores de narrativas etnográficas do e no meio urbano de Porto Alegre uma vez que, através de ambas as ações, os usuários poderiam explorar melhor o conhecimento local do fenômeno do "desencaixe" do tempo e do espaço tão característico da Modernidade. Trata-se de evitar ordens discursivas acerca das transformações dos cenários da vida coletiva em Porto Alegre e a tendência de transformar coleções etnográficas em depósitos ordenados de uma cultura material, dispostas numa lógica evolutiva ${ }^{6}$.

A criação do site compreende, portanto, uma proposta de exposição de coleções de documentos etnográficos em telas que se afastam da idéia de recuperação de uma história linear de estilos de "viver a cidade" segundo a realização racional de periodização do tempo no tratamento espacial da memória.

Da mesma forma, considerando-se a intenção da compreensão do microcosmo social que pulsa no interior da vida urbana porto-alegrense, tem sido avaliado também o estudo da poética do detalhe que envolve o tratamento da estética de "altafidelidade" da vida cotidiana dos seus habitantes no sentido de essa permitir ao usuário do site "inferir" as macronarrativas acerca da vida urbana.

Explorar a estética do fragmento, do ponto de vista formal da arquitetura do site, implica, assim, o trabalho de apresentação dos ritmos das transformações nas formas de vida social em Porto Alegre nos termos dos intervalos de espaço-tempo através dos quais a comunidade local se configura. O recurso dos experimentos

\footnotetext{
${ }^{4}$ Cf. André LEROI-GOURHAN, Le geste et la Parole, Paris, Albin-Michel, 1964.

${ }^{5}$ Ver a respeito, a obra de O CALABRESE. A idade neo-barroca. Lisboa, Edições 70, 1987.

${ }^{6}$ Ver a respeito, as críticas de Lilian M. SCHWARCZ, O espetáculo das raças,. São Paulo, Cia das Letras, 1993, em torno do tema das formas de apresentam dos documentos etnográficos para o caso dos museus no Brasil.
} 
etnográficos, com base na criação de hipertextos multimídia, podem, futuramente, dar conta de tais questões.

No momento, o desafio que temos enfrentado é o de se pensar captar o simbolismo de morfologias irregulares (em seu apelo às formas informes) na construção das telas de consulta, isto é, a elaboração de "enquadres" visuais que possibilitem apresentar as transformações nos territórios da vida urbana de Porto Alegre/RS como fruto dos dramas sociais destilados pelos fenômenos culturais aí produzidos.

Neste ponto, cabe salientar que as formas arquitetônicas, as texturas espaciais e as formas das manifestações artísticas e culturais que se desenrolam no teatro da vida urbana local, segundo têm apontado as pesquisas junto aos habitantes de Porto Alegre, repousam sobre a impressão de sua transformação interna permanente. Aderindo-se, assim, ao estilo flutuante e difuso através do qual o mundo urbano se revela aos olhos de seus habitantes e seus "mapas mentais", a paisagem de Porto Alegre vem sendo explorada como impressão de conjunto, com ambiências e atmosferas centradas em torno da "estética da desordem"7.

Apresentar uma visita guiada a partir do fragmento de uma estória em torno da Cidade adquire, na arquitetura do site, uma forma própria, sui generis, de se operar com o teatro da vida urbana como parte de mapas mentais de seus moradores, dando à arquitetura da tela uma geometria que deverá ser bastante peculiar.

Nos experimentos até agora realizados temos buscado, precisamente, disponibilizar fragmentos de imagens da antiga Porto Alegre e de suas estórias, incrustados na vida urbana local, para, logo após, situá-los no seu contexto de origem, exigindo do usuário uma ruptura com uma temporalidade fundada na construção de uma historicidade de fatos, ao despontar, de forma evidenciada, uma idéia da memória como reconstrução, fabulação ${ }^{8}$.

Ao se explorar a idéia de fragmento buscam-se os traços de um tempo e de um espaço concreto de representação da memória e do patrimônio locais para o usuário do site, visando restaurar a idéia da cidade como uma obra moldada e configurada pelo depósito de muitos gestos e intenções dos grupos humanos que nela habitaram, isto é,

\footnotetext{
7 A propósito do trajeto imaginário dos habitantes das cidades segundo a idéia de mapas mentais, ver LINCH, K. A imagem da cidade, Lisboa, Edições 70, s.d.

8 Pensa-se aqui no cruzamento das idéias de autores como Gilbert DURAND Les structures anthropologiques de l'imaginaire, Paris, Dunod, 1984 e R. GIORDANIM, De l'utilisation des témoignages oraux: aspects deontologiques. in: Etnologie Française, nouvelle série, tome $8, \mathrm{n}^{\circ} 4$, Paris, octobre/décembre, 1978, para o caso do tratamento das formas de exposição dos documentos em telas de consulta.
} 
"los tesoros culturales de una época"".

Todo o trabalho de apresentação, ao usuário, da sobreposição e da consolidação de ritmos e instantes que regem a vida urbana local como produto de diversas tradições urbanas que estão em competição entre si tem sido, até o momento, o grande desafio da pesquisa.

Para o caso aqui apresentado, vimos explorando o processo, por exemplo, de decomposição de prédios, destruição de ruas, transformação de bairros, construção de viadutos, pontes e túneis, retificações de percursos e aterramentos, aberturas de avenidas, etc. como experiências dramáticas para os habitantes de uma grande cidade, na medida em que conservam a possibilidade de, através de tais incidentes/acontecimentos, agenciar a dialética lembrança-esquecimento que preside os jogos da memória.

Há, portanto, no processo de destruição e reconstrução da cidade, uma singularidade específica. Interpretar a cidade como detalhe e fragmento implica considerá-la a partir da metáfora da ruína. Isto é, a cidade como o ponto de encontro entre o estudo da memória da civilização urbana local e a adesão dos habitantes ao processo de destruição de seus territórios.

Longe de ser um objeto-depósito, a Cidade concebida como um objeto temporal possui a capacidade de absorção de todas as histórias dos grupos humanos que por ali passaram tanto quanto de dissolução de seus signos culturais, os se quais tornam, aqui, objetos etnográficos, ou seja, pré-textos para a geração de novas estórias a serem narradas.

Do ponto de vista da configuração do site, recorre-se tanto à presença de morfologias estáveis nas manifestações culturais da Cidade, em seu apelo estético à ordem e à simetria na configuração do fenômeno urbano do Brasil, quanto de morfologias irregulares e instáveis que consolidam, a longo prazo, as suas atuais formas informes $^{10}$.

Ao contrário de cortejar a monumentalidade e os "objetos-mortos", nosso objetivo consiste em contemplar a poética que agencia o tempo "em situação" e que

\footnotetext{
9 Cf. G. SIMMEL, Concepto de la Tragédia de la Cultura y otros ensayos. Madrid, Revista de Occidente, 1935.

${ }^{10}$ Cf. expressão cunhada por G. DORFLES, Elogio a Desarmonia, Lisboa, Martins Fontes, 1986, e amplamente explorada na compreensão da estética da desordem como dimensão significativa do arranjo das estruturas espaço-temporais da paisagem urbana moderno-contemporânea.
} 
coloca em cena o movimento de decomposição como problema aos grupos humanos ${ }^{11}$.

Nesses termos, consideramos que se a memória de uma cidade é, por um lado, monumental, por outro, ela é vivida no percurso cotidiano dos seus habitantes nas ruas, nas praças, etc. Resgatar os itinerários dessa memória como espaços de encenações simuladas da vida coletiva de um grande centro urbano, como o caso de Porto Alegre, é colocar o processo de criação da arquitetura do site no bojo das atividades permanentes da representação social da própria gênese do seu patrimônio etnológico local

Parte do processo de "resgate documental" de coleções etnográficas a serem disponibilizadas no site tem sido orientada, portanto, no sentido de explicação do ato de destruição que está no bojo dos jogos da memória, o que consiste em pressupostos que é justamente o estatuto cognitivo das representações dos sujeitos humanos num determinado contexto sócio-histórico que o capacita a nele habitar.

No caso da concepção do site, o fenômeno da eterna destruição e reconstrução dos territórios da vida urbana porto-alegrense pode ser visto, aqui, sob a ótica da forma como os habitantes renovam o seu passado urbano. Ou seja, as utopias urbanas do passado são uma espécie de depósito de formas e conteúdos esparsos através dos quais os habitantes da cidade relacionam-se com as suas vivências contemporâneas. Em se tratando de uma estética urbana pautada pelas distopias do passado, o que se pode observar no Brasil é que a Cidade-ruína é a expressão do conjunto de intenções e de comportamentos de homem brasileiro diante do Tempo.

Nesses termos, diferentemente do uso convencional dos sites já pesquisados, presos ainda às "evidências materiais da história" de Porto Alegre, a criação da página WEB proposta tem sofrido as influências das investigações das diferentes formas de apropriação e criação das memórias do social dos moradores da cidade de Porto Alegre, fazendo-se uso do ato de destruição (desconstrução) de um acervo cultural um movimento único de pesquisa do conhecimento da Cidade segundo seu enfoque como objeto-temporal.

\section{Registros do tempo, inovações tecnológicas e museologização do mundo}

Inserindo-nos, assim, no processo de reflexão crítica a respeito do processo de museologização do mundo, pela via do "progresso da memória escrita e figurada da Renascença" tal qual aponta Le Goff ${ }^{12}$, a disposição arquitetural do site a ser criado

\footnotetext{
${ }^{11}$ VATTIMO, G. Les aventures de la différence. Paris, Editions Minuit, 1985.

${ }^{12}$ Cf. J. LE GOFF, História e memória. Campinas, ED. UNICAMP, 1990.
} 
busca explorar o universo das novas tecnologias no tratamento documental dos jogos da memória que se processam no mundo urbano contemporâneo.

A partir de tais considerações, propomo-nos aqui alguns comentários pertinentes ao trabalho que vimos realizando de criação de um Museu virtual no sentido de delimitar suas filiações e rupturas com o tema de uma cultura visual de cunho "museológica" que se apresenta no mundo urbano contemporâneo e cujo sustentáculo tem sido a produção e o consumo culturais da imagem do Outro.

Sem dúvida o século XX foi o século da memória. As ciências, a literatura, as artes, enfim, foram múltiplas as formas de tradução da memória do mundo. O contexto das transformações na organização das formas da vida social nos grandes centros urbano-industriais, o industrialismo, o surgimento de uma cultura do espetáculo e as ilusões associadas ao progresso da técnica como parte constituinte do agenciamento humano do tempo ${ }^{13}$ corresponderiam aos experimentos com a técnica da fotografia e à invenção do cinematógrafo, em fins do século XIX, até finalizar, nos dias de hoje, com o computador e as redes digitais e eletrônicas ${ }^{14}$.

A técnica de registro documental de fatos, eventos e acontecimentos sociais por meios tecnológicos cada vez mais sofisticados (fotografia, cinema, vídeo, as novas tecnologias da informática) tem revelado ao homem moderno a sua capacidade de desvendar mundos sensíveis que não eram antes percebidos: a poesia dos atos e falas humanas ordinárias e cotidianas, por exemplo, o conhecimento e a precisão dos fatos observados pela ciência; a composição dos movimentos que encerram as ações de homens e animais em seus detalhes estruturais, o armazenamento de informações através de programas de computadores, etc.

Impossível não se perceber que as atuais invenções tecnológicas das redes eletrônicas e digitais, na condição de suportes materiais da memória, são herdeiras legítimas do ideário da Modernidade que conforma um olhar humano sobre o mundo, cuja finalidade permanece sendo, precisamente, observar e dissecar a realidade para melhor descrevê-la, escrutiná-la, dominá-la e, correlato a esse processo,

\footnotetext{
${ }^{13}$ Referimo -nos aqui a inúmeros desses aspectos, tais como a eletricidade como fenômeno que orienta o controle dos ritmos naturais do tempo nos grandes centros industriais, a formação de grandes impérios coloniais e o encurtamento das distâncias que separavam o homem ocidental de povos e civilizações, antes, longínquos; o crescimento de consumo cultural do exótico e do bizarro; o desenvolvimento da industria do turismo e sua sede voraz de novas paisagens humanas e naturais, etc.

${ }^{14}$ Cf. SUBIRATS, E. A Cultura como espetáculo,. São Paulo, Nobel, 1989.
} 
armazenar suas informações ${ }^{15}$.

Entretanto, no momento em que o olhar do homem contemporâneo pretendeu não só a dissecação, mas a restauração do átomo fotográfico, através da simulação dos seus movimentos sucessivos projetados na sala escura, revelando tudo o que antecede a cena registrada nos termos de uma hierarquia de instantes, a proto-história da imagemsíntese e a tela do computador se anunciam em sua pretensão de dispositivos mais aptos a registrar a matéria do tempo.

Universalidade e interatividade, a memória eletrônica e digital, aplicadas ao tema da criação do museu virtual, na linha dos comentários de Roger Chartier, a propósito do texto eletrônico, recolocam, na contemporaneidade, o "antigo sonho kantiano" que inspirou o homem moderno: o empreendimento enciclopédico, isto é, que qualquer homem pudesse ser "ao mesmo tempo leitor e autor, que emitisse juízos sobre as instituições de seu tempo (...) e pudesse refletir sobre o juízo emitido pelos outros"16. Nesta medida, da mesma forma que a fotografia relaciona-se à ambiência psicossocial moderna ${ }^{17}$ ao permitir que as formas do mundo e as imagens do Outro pudessem ser perpetuadas, copiadas, fabricadas, multiplicadas e distribuídas, as novas redes eletrônicas e digitais refletem o processo de manipulação das estruturas espaçotemporais criadas no bojo do mundo contemporâneo.

Assim, ao se conferir, de forma irrestrita, às novas tecnologias o sonho da disponibilidade universal das palavras enunciadas e das coisas representadas ${ }^{18}$ pela forma como elas permitem organizar, classificar, ordenar e armazenar informações "segundo um sistema de pesquisas de múltiplas entradas nos textos, nas imagens e nos sons que fazem parte do patrimônio universal da humanidade, ${ }^{19}$ corre-se o risco de se esquecer sua vinculação a uma cultura visual determinada.

Nesse aspecto, as novas possibilidades de museologização, advindas da memória eletrônica e digital e mediada pela conformação da tela do computador, conforme muitos autores já apontaram, nasce e se alimenta de velhas e antigas formas de registro

\footnotetext{
15 A idéia, por exemplo, do fuzil fotográfico, disparando a intervalos regulares, de Demeny, e do uso de inúmeras câmeras para capturar o fenômeno em suas diferentes posições (Marey), são um exemplo do que vimos afirmando, cf. A MACHADO, Pré-cinemas \& Pós-Cinemas, São Paulo, Papirus, 1997, e E. BARNOW, El documental, historia y estilo, Barcelona, GEDISA, 1996.

${ }^{16}$ Cf. Kant, citado por R. CHARTIER, A aventura do livro, do leitor a navegador, São Paulo, UNESP, 1999, p.134.

${ }^{17}$ Cf. W. BENJAMIN, Walter Benjamin”. Coleção Grandes Cientistas Sociais. São Paulo, Ática, 1991. Texto 8. PequenaHistória da Fotografia.

18 Op. cit. 135.

${ }^{19}$ Cf. R. CHARTIER, op. cit,. p.136.
} 
documental das imagens do tempo, segundo seus diferentes suportes físicos. Por um lado, a representação da pintura renascentista, passando, mais recentemente, pelo advento da fotografia, do cinema, do vídeo e da televisão, por outro, o advento da imprensa e "o surgimento dos livros e das novas formas de leitura e escrita daí decorrentes", dando-nos conta aqui que, na Idade Média, “ó livro sobre a mesa” tanto quanto a pintura, na Renascença, tornaram-se precursores da idéia moderna de tela/enquadre: "um retângulo plano funcionando como janela de um mundo virtual" 20 .

\section{Projeções do tempo, os museus e a cultura visual da tela}

Importa salientar-se que nos mais diversos Museus é a tela retangular e plana da Renascença aquela que se adota como forma de exposição. Uma tela-janela que exige a posição frontal do observador e que, opondo-se a ele, se torna uma paisagem a ser contemplada, mas jamais manipulada. Nestes espaços museais, a tela clássica alude a uma janela para um outro mundo, afirmando-se, assim, como espaço de representação cuja escala é substancialmente diferente do espaço onde está situado o corpo do próprio observador $^{21}$.

Da tela clássica da pintura renascentista às formas das exposições fotográficas em Museus, em tempos mais recentes, permanece ainda a presença da tela estática e fixa nas formas de exposição, apresentando ao observador o mundo visto por um olho singular: um ponto de vista fora da duração, revelado como atemporal. Eliminando-se o movimento, as formas de exposição em Museus, seja através da pintura seja da fotografia, tendem a aprisionar o sujeito e o objeto da representação numa apresentação de um mundo estável, imóvel, eterno.

Há, entretanto, diferenças sutis a serem observadas entre a pintura renascentista e a fotografia nos termos da técnica de registro documental das imagens do tempo. Sem dúvida, a técnica fotográfica difere da pintura na forma como se opera aí o registro do tempo uma vez que na fotografia the different parts of the image correspond to different moments in time $e^{22}$, isto é, todas as partes da imagem-objeto são expostas

\footnotetext{
20 Segundo L. MANOVICH, “An Archeology of computer screen”, In: NewMediaTopia, Moscow, Soros Center for Contemporary Art, 1995, os antigos afrescos e mosaicos, ao longo desse trajeto, não poderiam ser aqui considerados como "tela/enquadre", embora representem uma tradição alternativa que encorajava o movimento do observador, ainda que não pudesse se destacar da própria arquitetura do lugar.

${ }^{21}$ Passados séculos, segundo L. MANOVICH, op. cit., essas características, não por acaso, ainda serão aquelas que configuram, nos dias de hoje, a tela do computador: horizontal format is referred to as ' landscape' while the vertical format is referred to as 'portait mode'.

${ }^{22}$ Cf. L. MANOVICH, op. cit. p. 6.
} 
simultaneamente ao registro documental, o que significa aqui pontuar que se altera a idéia tradicional do registro temporal veiculada pela pintura renascentista até o surgimento do impressionismo. No caso da fotografia foi precisamente a rapidez do esquadrinhamento dos registros da imagem-objeto, e por sua aparência de fixidez, que permitiu à imagem-técnica, na modernidade, elevar-se ao rang de "imagem".

No caso de uma cultura visual que vem se consolidando no interior das modernas sociedades contemporâneas, o nascimento do cinema desestabiliza parcialmente o quadro aqui descrito, isto é, o antigo caráter frontal, retangular e estático da tela/enquadre da pintura renascentista. Entretanto, a criação de uma tela dinâmica como forma de exposição de registros das imagens do tempo se consolida a partir do lugar de imobilidade do espectador ${ }^{23}$. Isso porque o princípio da tela cinematográfica pressupõe que as diferenças de escalas entre sujeito e o objeto da representação se diluam na medida em que o corpo imóvel do espectador seja subjugado à ambiência da sala escura ${ }^{24}$.

Nesse sentido, a passagem das origens renascentistas da técnica fotográfica para a "tela dinâmica" do cinema, onde a imagem altera-se com o tempo, produz certas alterações nos padrões do tratamento conceitual dos registros do tempo e suas formas de exposição tanto quanto modificações nas formas de produção e consumo cultural da imagem-técnica.

A idéia de temporalidade, portanto, da tela clássica dos Museus, em que os dispositivos da imagem são estáticos, difere, assim, daquela veiculada pela tela dinâmica cujos dispositivos da imagem movem-se no tempo presente. Nesse sentido, se, por um lado, as formas de exposições adotadas pelos atuais Museus cumprem ainda, rigorosamente, sua filiação à pintura renascentista ao explorar a tela clássica, face à qual o espectador adota uma visão frontal (confrontando-se com escalas de representação diferenciais), por outro, o cinema, o vídeo, as instalações, mais contemporaneamente, inauguram a presença das atuais telas de computadores na ambiência museal ao investirem progressivamente no processo de imersão do espectador numa tela dinâmica onde os limites entre o espaço da representação e o espaço físico se esvanecem.

Cabe, assim, reconhecer-se que, hoje, no âmbito de Museus os mais diversos, além da fotografia, o cinema, o vídeo e as instalações têm participado como

\footnotetext{
23 A propósito, ver L. MANOVICH, "Computer simmulation and the history of illusion". In: Digital Delirium, A Kroker e M Kroker,(Orgs), New York, St Martin's Press, 1977, "(WWW.apparitions.ucsd.edu/ manovich).

${ }^{24}$ Ver, a respeito,a obra de E MORIN, Le cinéma ou l'homme imaginaire, Paris, Gonthier, 1958.
} 
instrumentos eficazes de tratamento documental, ainda que participem diferencialmente, cada qual a seu modo, de uma cultura visual determinada pelo nascimento de novas formas de tratamento e registro documental do tempo nas modernas sociedades urbanoindustriais. Ou seja, salas de exposições compartilham a ambiência museal com salas de projeções de filmes, instalações e quiosques interativos como formas distintas de disponibilizar acervos documentais diversos aos seus usuários.

A exibição de coleções à admiração pública, onde o espectador situa-se fora do espaço da representação, no sentido de manter sua distância psicológica da imagem projetada na tela, mescla-se à tendência contemporânea de torna esse espectador cúmplice do olho ilusionista da tela dinâmica, que lhe permite ver, observar, participar, do melhor ângulo possível de tais coleções. Museus enciclopédicos incorporam à sua pretensão de reunir exemplares das obras da cultura humana o processo de passagem da tela estática para a tela dinâmica como dispositivos de apresentação de seus acervos. Galerias e salas de exposições dividem o espaço dos Museus com as salas escuras de projeção, não resistindo ao dinamismo da tela cinematográfica e à sua ilusão cinemática, onde os espectadores imóveis e passivos, situados em frente à tela, assistem às imagens que são projetadas por um "engenho" encoberto, atrás de suas cabeças ${ }^{25}$.

$\mathrm{Na}$ maioria desses dispositivos, entretanto, à exceção das instalações e dos quiosques interativos, a realidade representada é recortada pelo retângulo de uma tela que constrói o mundo de um ponto de vista subjetivo a partir de dois sentidos: o espaço corporal do espectador e o espaço virtual de uma imagem na tela estática, situados em escalas de espaço- tempo diferenciais. Somente os primeiros dispositivos propõem usos, manuseios e intervenções por parte do espectador como aspecto central do tratamento de coleções museais, atribuindo-lhes um lugar de autoria de trajetos e percursos, e não mais uma posição periférica diante da tela/enquadre. $\mathrm{O}$ advento da realidade virtual (VR) no âmbito das formas de exposições de conjuntos documentais certamente deverá seguir este processo de incorporação das novas tecnologias no interior do ambiente cultural dos Museus, papel que as instalações, até certo ponto, já vem cumprido.

\footnotetext{
25 Acopla-se à ambiência silenciosa dos Museus, tal qual a atmosfera que presidia a ambiência das antigas bibliotecas monásticas do séc. XIII e XIV, cf. R. CHARTIER, op.cit., o silêncio das salas de projeção como uma das condições para que o dinamismo da tela cinematográfica possa se processar além da necessária imobilidade do espectador. Cf. L.MANOVICH, op. cit., pp. 11-15, esta ambiência ilusionista das salas de cinema difere grandemente dos hábitos mais que usuais da ambiência de rumores que se configura nas projeções de filmes na televisão e no vídeo.
} 
Filiações e Rupturas de tradições visuais: a tela/interface como espaço de representação

Roger Chartier em suas reflexões em torno das práticas de leitura e escrita pela via das novas tecnologias reconhece que o "mundo do texto eletrônico", além de criar uma distância do leitor com relação ao livro, coloca-o "fora de seus gestos corporais usuais",26 , pois o universo que ele contempla "é forçosamente um mundo de telas."

Da mesma forma, no âmbito museal o uso dos atuais computadores e de seus dispositivos, onde interfaces e realidade virtual (VR) combinam-se para um outro regime de imagens com base na idéia de uma tela dinâmica, colocam as formas convencionais de tratamento e exposição dos conjuntos documentais frçosamente no mundo das telas-janelas dinâmicas com a qual o observador interage, segundo um processo de identificação singular ${ }^{27}$.

Vejamos, aqui, em particular, o caso do advento da dinâmica da tela/interface dos computadores no âmbito dos espaços museais. Conforme vimos afirmando, na tela cinematográfica das salas de projeções, a imagem cria no observador uma ilusão de realidade que exige do espectador uma suspensão de suas antigas formas de se apropriar das representações do mundo na medida em o ilusionismo gerado pela imagem em movimento só é atingido por meio de seu despreendimento do meio circundante.

Diferentemente do cinema, onde a imagem movimenta-se com independência do observador situado em posição neutra, agora o espectador deve se mover em torno do espaço físico para experienciar o movimento no espaço virtual. Ele deve, então, operar com a imagem para que seu movimento se processe, através de dispositivos especialmente criados para tais fins ${ }^{28}$.

Os avanços das novas tecnologias no sentido da VR (realidade virtual) têm permitido um aprimoramento da moderna cultura visual da tela "dinâmica" no sentido da tendência à supressão da própria ela/enquadre. Isto é, com o advento da VR e seus dispositivos (capacetes, luvas, joysticks, óculos, etc.) conectados por cabos ao computador, a imagem-movimento tende a preencher completamente o campo de visão

\footnotetext{
${ }^{26}$ Cf. R. CHARTIER, op.cit, p.13.

${ }^{27} \mathrm{Da}$ mesma forma, cf. A MACHADO, op. cit, poder-se-ia aprimorar-se as origens da tela original do cinema aos antigos espetáculos ilusionistas do sé. XVIII e XIX (lanterna mágica, fantasmagorias, teatro de sombras, dioramas, etc.) que, por sua vez, remeteriam às pinturas paleolíticas nas cavernas em que o homem já estaria dentro de um regime de imagens cinematográfico, antes mesmo da "invenção" do próprio cinema.

28 Segundo L. MANOVICH, An archeology...,op. cit., p.16, o corpo do espectador torna-se "a giant mouse, or more, a giant joystick", no sentido de que no momento em que se move o mouse, o usuário do computador move seu próprio corpo.
} 
do espectador, que é obrigado, então, a situar-se, por efeitos de simulação, em outro espaço-tempo onde the real physical space and the virtual simulated space coincidem. Nesse ponto, sim, podemos afirmar, com propriedade, que estaríamos rumando para a criação de um museu virtual strictu sensu ${ }^{29}$.

Até esse ponto ser atingido, resta-nos os casos mais "convencionais" de uso das novas tecnologias em Museus, em que a tela funciona não mais como tela/enquadre, mas como uma janeh-interface, podendo se desmembrar em muitas janelas, concebidas como uma coleção de diferentes blocos de informações, todos de igual importância para o seu usuário $^{30}$. Esse mesmo fenômeno é igualmente reconhecido por R.Chartier ${ }^{31}$ ao observar a revolução nas práticas da leitura e da escrita do livro, quando de sua passagem à memória eletrônica ou digital - isto é, "sem inscrição no papel" - pela possibilidade que a mesma oferece de "embaralhar, entrecruzar, reunir" informações e dados: todos os traços que, segundo o autor, indicam uma revolução nas estruturas do suporte material da memória. O manuseio do livro "eletrônico" passa, assim, pelos mesmos dispositivos que criam a interface homem/computador no caso de um museu virtual: teclas, mouse, tela.

Sem dúvida, coerentemente com o que vimos afirmando até o momento, a tela dinâmica do computador se insere no curso da conformação de uma cultura visual singular às sociedades moderno-contemporâneas: a presença de uma informação visual numa tela retangular e plana, colocada a uma certa distância do olho do observador, dando-lhe a ilusão de "navegar" virtualmente no espaço e no tempo.

Da mesma forma, a tela dinâmica dos atuais computadores vincula-se às formas usuais de registro documental do fenômeno espaço/tempo que estão intimamente associadas, por seu turno, à conformação de uma sociedade do espetáculo. Isto é, um sociedade ávida de inovações tecnológicas, seduzida pela "fantasia da biblioteca", pelo culto do Deus in machina ${ }^{32}$ e adepta da idéia de Aventura ${ }^{33}$. Ou seja, o "mundo de telas" que nos fornecem as atuais redes digitais e eletrônicas nasce e floresce à sombra de uma indústria de entretenimento cada vez mais sofisticada e continua a

\footnotetext{
${ }^{29}$ Cf. L. MANOVICH, op. cit., p. 4

${ }^{30}$ Inúmeros autores aludem aqui às aproximações da tela do computador com as formas usuais televisivas do zapping onde não há a tela que predomine na atenção do espectador, permitindo-lhe a coexistência de imagens em apenas uma tela, e onde o espectador pode assistir a inúmeros programas simultaneamente.

${ }^{31}$ Cf. R. CHARTIER, op. cit.

${ }^{32}$ Cf. G. DURAND, Science de l'homme et Tradition, Paris, Berg International, 1979, pp. 98-99 em suas análises em torno do "modernismo ocidental" e suas fábulas progressistas.

33 A própria expressão "navegar na internet" pode ser aqui sugestiva para o caso do estudo das atuais redes digitais e eletrônicas como objeto da Antropologia da viagem
} 
disponibilizar, como noutros tempos, o consumo cultural de formas representacionais associadas, agora, à idéia de complexos de informações e dados ${ }^{34}$.

Se a tela dinâmica do computador remonta à ingenuidade dos espetáculos ilusionistas e ao nascimento da indústria do entretenimento das sociedades urbanoindustriais de fins do séc. XIX, a conformação das telas-interfaces e sua condição de interatividade vinculam-se, a outros processos de formas representacionais da imagem e de práticas sociais a elas associadas e que são, por sua vez, menos glamourosos. O advento da tela/interface desponta como parte do desenvolvimento tecnológico de dispositivos de segurança militar durante a I Grande Guerra.

Foi a necessidade de prospeção do espaço aéreo durante a I Grande Guerra, transmitida via radar, que originou a tela/interface dos atuais computadores ao permitir um mapeamento simultâneo de imagens de áreas de segurança militar para a tela de um monitor $^{35}$. Do processamento da informação com base em códigos algoritmos e sua disponibilização em redes de informação, através de um comando central, é que derivariam, então, as atuais interfaces entre o homem e o computador ${ }^{36}$. O passo seguinte seria o que, mais recentemente, não cessa de acontecer: a criação de programas gráficos de computador interligados para n colocar e retirar informações, culminando com a criação de programas gráficos interativos ${ }^{37}$. Pode-se afirmar, então, que a tela/interface dos atuais computadores só atinge seu grau de maturação quando adentra, com os softwares de animação, a realidade em 3D e seus efeitos de simulação do funcionamento da mente humana, grande parte deles dirigida, primeiramente, à indústria da guerra e à conquista espacial ${ }^{38}$.

\footnotetext{
${ }^{34}$ Cf. J LANIER, citado por L MANOVICH, From the externalization of Psyche to the Implantation $\quad$ ftecnology, WWW.apparitions.ucsd.edu/ manovich), WWW.apparitions.ucsd.edu/ manovich, p. 5: "You can play back memory through time and classify your memories in various way, You'd be able to run back through the experiental places you've been in order to be able to find people, tools".

${ }^{35}$ Cf. MANOVICH, An archeology...,op. cit., há diferenças para o caso do computador e da televisão: no primeiro, a imagem é produzida por um esquadrinhamento seqüencial, em forma circular; no segundo, a seqüência de esquadrinhamento da imagem é horizontal.

${ }^{36}$ Cf. L.MANOVICH, idem,op. cit., em 1949, o SAGE, setor de defesa aérea dos EUA, já havia desenvolvido muitas das interfaces que existem hoje nos computadores para uso doméstico: a caneta luminosa (precursora do mouse), a tela não só construída para disponibilizar as informações armazenadas, mas projetada no sentido de permitir o acesso aos comandos do computador.

37 A propósito, ver MANOVICH, An archeology...,op. cit., p.9, segundo o qual "a new paradigm emerged - the simulation of an interactive three-dimensional environnement without a screen.(..) The screen disappeared. It comp letely took over the visual field."

38 Cf. L. MANOVICH, From the externalization..., op. cit., p.1: "Unobservable and itnerior processes and representations were taken out of individual heedas and put outside - as drawing, photographs and othe visual formas. Now they could be discussed in public, employed in teacheind and propaganda".
} 


\section{As mídias eletrônicas e digitais: naturalismo, realismo e metarealismo}

Apesar de se reconhecer que o advento do ilusionismo visual das novas tecnologias origina um novo tipo de interação entre o corpo do espectador e a imagem, no que tange ao tema da tela-interface no processo criação de Museus virtuais e as formas de exposição de conjuntos de informações e dados, é importante ressaltar que estamos ainda no interior de uma cultura visual de cunho museológico. Isto é, o advento da realidade virtual percorre a obsessão com o naturalismo da imagem da cultura visual museal associada ao nascimento, no século XIX, dos Museus de cera e a criação dos dioramas e panoramas ${ }^{39}$ dos Museus de história natural. Espaços representacionais que buscavam o mergulho do observador numa janela-paisagem imaginária cuidadosamente recriada por computação gráfica em 3D, tal qual Alice no país das maravilhas, cujas escalas e proporções são responsáveis por seus efeitos de realidade ${ }^{40}$. A realidade virtual continua, portanto, essa tradição de simulação onde se busca a conexão entre os espaços físico e virtual, sendo o primeiro deles progressivamente abandonado.

Nesse sentido, a produção dos efeitos de simulação, interatividade e telepresença característicos da imagem digital e eletrônica é presidida pela obsessão da indústria da mídia e das tecnologias da informática com o ilusionismo visual da imagem digital, ou seja, sua capacidade de capturar, e mesmo ultrapassar, o naturalismo e realismo fotográfico e fílmico ${ }^{41}$. Perspectiva linear, efeito de profundidade de campo, arranjo particular de tom e cor, etc. tornaram possível, com a ajuda dos efeitos computacionais, a recriação da aparência pictórica, fotográfica ou fílmica da imagem, tornando-a "natural" ${ }^{42}$, tornando-a cada vez mais indistinta da imagem digital, embora essa seja

\footnotetext{
${ }^{39}$ Os dioramas são telas-janelas em que a escala de representação está na mesma escala do mundo humano pelo fato de esse espaço virtual simular na tela/enquadre o espaço físico real, produzindo o ilusionismo da imagem e seus efeitos de realidade. Os panoramas, diferentemente do anterior, são ambiências que criam, num espaço de 360 graus, janelas-cenários, onde o observador ocupa o seu lugar central, sendo encorajado a mover-se em torno dessa área de visão central, que permite o estado de imersão na cena recriada.

${ }^{40}$ Cf. L. MANOVICH, An archeology...,op. cit., poder-se-ia pensar, para o caso da tela dinâmica, em 3D, que seus jogos de simulação no computador guardassem alguma filiação aos afrescos e mosaicos presentes em capelas, igrejas e palácios, o que não é o caso uma vez que neles o espaço físico e real das ações não está subordinado ao espaço virtual, enquanto nos panoramas é a "tela" que desaparece.

${ }^{41}$ Acredita-se que a tendência é que o próprio computador se torne invisível quando as interfaces com o homem atingirem sua feição completamente " natural”. Imagens computadorizadas avançaram, nos anos 70, para sua feição cada vez mais representacional e fotorrealismo, através do fotorealismo de imagens-síntese, em 3D, com programas de pintura, de texturização, de sombreamento, etc. até chegar-se no Photoshop, que manipula a fotografia através de uma imagem criada em computador, nos anos 80.

42 Segundo L. MANOVICH, Computer simulation and the history of illusion, WWW.apparitions.ucsd.edu/ manovich, p.1, "to achieve this integration, computer-generated images had to be degraded; their perfection had to be diluted to match the imperfection of film's graininess" Assim, se a imagem digital em 3 D gerada pelo computador avança no aprofundamento da idéia de profundidade de campo, o vídeo digital através de filtros especiais simula o grão do filme, e assim sucessivamente.
} 
feitas por pixels ou representada por equações matemáticas ou algoritmos.

O desafio do uso da imagem-síntese nas formas de exposição de acervos de documentos em Museus (Web sites, mundos virtuais, jogos de computador e outros tipos de aplicações multimídia) está associado ao próprio passado e ao presente da incorporação das imagens fotográficas e cinematográficas nas formas usuais de tratamento dos acervos documentais para o grande público.

Por outro lado, o ilusionismo visual possível, através do computador, envolve outros sentidos que não só a visão, ou seja, o engajamento ativo do corpo do espectador, a acurada simulação de objetos físicos e de fenômenos naturais, a simulação de modelos humanos e suas reações, emoções, estados, comportamentos, etc ${ }^{43}$.

Operações como copiar, colar, adicionar, multiplicar, comprimir e filtrar lembram dimensões inerentes ao sentido da percepção humana, sendo que em tais operações a imagem pode ser pensada como a interface entre o homem e o computador, isto é, a interface onde interagem a lógica do computador (dados codificados numericamente pela manipulação de algoritmos, automação, variabilidade, simulação) e a lógica humana ${ }^{44}$. Diferentemente do seu antigo estatuto na tela dinâmica, a imagem interface como condição de interatividade situa o espectador entre as técnicas tradicionais do ilusionismo que a imagem veicula e sua suspensão. O ilusionismo visual da imagem se esvanece, por exemplo, quando o espectador pode observar, através da tela do computador, as informações e os dados construindo-se no tempo, considerandose que as telas descem uma a uma, os textos vêm antes das imagens, e as imagens chegam em baixa resolução até serem, lentamente, refinadas.

Neste ponto, um espaço museal virtual não pode obedecer à lógica clássica das formas de exposição de conjuntos documentais nos Museus convencionais, considerando-se que a visitação em WEB sites sujeitam o espectador a diferentes tipos de atos cognitivos: analisar distintos conjuntos de informações, processar uma busca, iniciar suas aplicações, navegar através das páginas da tela, novamente iniciar outra busca, e assim sucessivamente, num mesmo tempo, através de múltiplas telas abertas,

\footnotetext{
${ }^{43}$ Cf. L. MANOVICH, An archeology...,op. cit., p.6, as imagens-sínteses geradas pelos computadores "is not an inferior representation of our reality, but a realistic representation of a different reality". Isto é, a imagem síntese representa o acontecimento futuro, contrariamente à imagem fotográfica tradicional que sempre aponta para o passado.

44 Cf. L. MANOVICH, An archeology...,op. cit., p.2, a nova lógica das imagens por computador deriva de uma nova mídia, isto é, "the visual culture of a computer age is cinematographic in its apppearance, digital on the level of its material, and computational (i.e., sofwares driven) in its logic".
} 
que vão lhe exigir sempre novas perguntas e novas respostas ${ }^{45}$.

\section{Paixões bibliófilas e museófilas e as distopias do passado}

$\mathrm{Na}$ trilha da polifonia das imagens que constituem o percurso de patrimonialização da memória nas sociedades urbano-industriais, é que a criação de um museu virtual de Porto Alegre visa explorar, como já afirmado anteriormente, na imagem-interface do computador, a natureza de suas formas informes ${ }^{46}$, isto é, a partir de múltiplos percursos/trajetos na paisagem urbana local a serem percorridos pelos seus usuários, onde se encontra presente a força do hibridismo de formas culturais que a cidade encerra em sua conformação histórica.

Isso porque, se, por um lado, o processo de museologização do mundo atende, assim, ao consumo de informações e dados, nos quadros de uma celebração do próprio homem ocidental, europeu, branco e civilizado - mantendo algum parentesco com os antigos cabinets de curiosité - por outro, ele traduz uma demanda arquivística cada vez mais presente à formação da cultura objetiva no Ocidente moderno, progressivamente voltada ao fenômeno do registro de coleções documentais com forte inspiração na idéia da "consciência histórica"47

Considerando-se assim que, no caso de Webs sites, o velho realismo da Modernidade passa por um processo de crítica a si-mesmo, em que o usuário não desconhece o ato ilusionista do qual participa, mas, generosamente, deixa-se dele participar, a criação de um WEB site inspirado nos jogos da memória ${ }^{48}$ do social em Porto Alegre, apontaria, assim, para os limites formais de se enfocar, nas formas de tratamento documental das representações em torno do patrimônio urbano local a imagem do Idêntico e do Simétrico como expressão peculiar à estética de produções culturais.

Nesse contexto, as interfaces homem-computador, no caso da criação de um "museu virtual", despontam como novas possibilidades de exposição de conjuntos de documentos etnográficos sobre o mundo urbano contemporâneo de Porto Alegre ao se

45 Cf. L. MANOVICH, An archeology...,op. cit., o ilusionismo vincula-se a ações tanto quanto a profundidade relaciona-se à superfície, a "janela para o mundo" ao painel de controle, etc..

46 A propósito ver A L.C da ROCHA, Le santuaire du désordre: l'art de savoir-vivre des tendres barbares sous les Tristes Tropiques, tese de doutorado, Paris V, Universidade René Descartes, Sorbonne, defendida em junho de 1994.

47 Trata-se aqui de se pontuar criticamente os limites possíveis das novas tecnologias na produção de textos etnográficos no que diz respeito aos temas da produção/criação/apropriação de imagens do Outro e do documental, tendo como foco de atenção seus vínculos com as transformações sofridas pelas noções de testemunho/autenticidade/verdade no cômputo do mundo urbano-contemporâneo.

${ }^{48}$ P-H. JEUDY, As memórias do social. Rio de Janeiro, Forense Universtária, 1990. 
constituírem em janelas através das quais podem ser apresentados lugares, pessoas, acontecimentos e situações que estão à milhas de distância no espaço e no tempo. Realidade, interatividade e telepresença tornam-se, pois, modos possíveis de ver, olhar e interagir com as imagens do tempo que nos permitem, hoje, as novas tecnologias digitais e eletrônicas.

Explorando-se o metarrealismo da imagem-interface que faz com que o sujeito oscile entre a ilusão e sua destruição, entre a imersão do observador na ilusão que retorna a ele para ser criada, e onde o observador pode fazer escolhas, redirecionar a narrativa e adicionar informações, a arquitetura do site que está sendo criada pretende, assim, explorar, junto aos usuários, o processo de conformação da civilização urbana em Porto Alegre. Pontua-se, nos percursos, trajetos e itinerários, a repetição arítmica de temas, de lugares, de cenários-tipos, de encenações-tipo, sob a pressão da serialidade de acontecimentos oriundos das utopias progressistas.

As visitas guiadas a serem propostas aos usuários do site apresentariam, assim, em telas de consulta interativas, a paisagem urbana local através da superposição de estruturas espaço-temporais diferenciais, operando-se com o atual cenário urbano de Porto Alegre como um sistema descentrado e aberto. É o tema da agitação temporal ${ }^{49}$ como espaço de representação que deverá, portanto, orientar a visita guiada no sentido de conduzir o usuário ao confronto com as formas de vida social diferenciais que a cidade contempla desde seus inúmeros mitos de fundação.

Em termos gerais, o site que está em fase de gestação, no que tange ao patrimônio cultural, artístico e histórico porto-alegrense, tem tomado os objetos e as manifestações culturais no mundo urbano de "outros tempos" como testemunhos de uma época, espécie de suporte material das lembranças-vestígios de uma comunidade na história, sendo, inclusive, a partir dessa "evidência" que se prevêem as consultas aos seus usuários.

No caso do uso das novas tecnologias voltado ao processo de recriação de um espaço museal virtual, há que se pensar, portanto, que no ilusionismo provocado pelos efeitos computacionais o observador interage com a representação. $\mathrm{O}$ antigo conceito de imagem transmuta-se em imagem-interface ou imagem-instrumento. Clicar, zonear a imagem ao mesmo tempo em que tomar decisões ou selecionar, caracteriza-se por uma dinâmica temporal singular de apropriação da tela dinâmica que prevê a relação do

\footnotetext{
${ }^{49}$ Cf. expressão de G. BACHELARD, A dialética da duração. PUF, Paris, 1989.
} 
usuário com os atos artificiais, incompletos e desconstrutivos da máquina do computador.

Nesse sentido, evocamos os comentários pertinentes de R. Chartier ao pontuar que a biblioteca virtual, ao sair de seus muros, na mesma medida em que acentua a proliferação de imagens, conduz ao gesto da destruição, em vez da exigência da conservação. Segundo o autor, cada vez mais, "um bom leitor é alguém que evita um certo número de livros, um bom bibliotecário é um jardineiro que poda sua biblioteca, um bom arquivista seleciona aquilo que se deve refugar ao invés de armazenar ${ }^{50 "}$.

Vale lembrar que o sujeitamento ao gesto de destruição que caracteriza o uso das novas tecnologias não se configura como único componente do caráter interativo da imagem no ambiente das redes, já que o sujeito diante da tela do computador oscila, freqüentemente, entre os papéis de observador e de usuário, seguindo a estória e atuando para que ela aconteça. Isso porque somente em certos espaços de tempo o usuário das redes eletrônicas e digitais está engajado numa narrativa cinemática; em outro momento ele é forçado ao ato: fazer escolhas, clicar, apertar botões, etc. Uma experiência temporal que o coloca no centro do jogo interpretativo, isto é, entre a transparência da tela do computador e sua opacidade.

O tema da memória eletrônica e digital agudiza, assim, alguns aspectos cruciais das modernas sociedades contemporâneas já apontados por $\operatorname{Simmel}^{51}$ nos termos da tragédia da cultura: a proliferação do universo de imagens de conjuntos documentais, no caso de um museu virtual, pode repetir o que se passa nos termos da biblioteca virtual, onde o antigo gesto de conservação pode vir a instaurar um novo gesto, o de destruição. Diferentemente do que se coloca para o suporte da memória fílmica e fotográfica presentes aos acervos dos Museus convencionais, pode-se pensar que todo conjunto de documentos que se possa reunir na tela do computador, para a criação de um WEB site, pode ser destruído no próximo click, sendo justamente tais gestos de destruição as condições das interfaces homem-computador que mantêm continuamente o caráter ilusionista da imagem eletrônica.

Nesse caso, o espaço de um museu virtual só pode adquirir uma feição antropológica se coloca o espectador no interior da profusão de obras da cultura, desafiando o tratamento museal dos jogos da memória e sua "nostalgia conservadora" quanto às "utopias ingênuas" que cercam o processo de patrimonialização do mundo na

\footnotetext{
${ }^{50}$ Cf. R. CHARTIER, idem, p. 127

${ }^{51}$ Cf. G. SIMMEL, op. cit.
} 
era da informática.

Para o caso dos "museus extramuros" que, até certo ponto, pretendemos, valeria o mesmo que R. Chartier comenta a respeito da criação das "bibliotecas sem paredes", ou seja, "pela primeira vez na história da humanidade a contradição entre o mundo fechado das coleções e o universo infinito do escrito perde seu caráter inelutável" ${ }^{" 52}$. Com as novas tecnologias, acredita-se que a busca do universal oferece a todos os indivíduos "o que poderia tornar mais potente o seu olhar sobre si mesmo e sobre o mundo da comunicação à distância de textos transformados, numerados e convertidos em textos eletrônicos, colocados em rede" ${ }^{, 53}$.

No caso aqui proposto, pensar o processo de museologização do mundo ${ }^{54}$ através da criação de um WEB site que tematize coleções etnográficas sobre as transformações da paisagem da vida urbana porto-alegrense é perseguir, de forma ainda mais acurada, uma reflexão em torno do tema da "obliteração das diferenças" no interior do empreendimento enciclopédico que formata as redes digitais e eletrônicas como uma das modalidades de uma cultura visual nas modernas sociedades complexas.

Em especial, para nós, trata-se de refletir eticamente a respeito dos perigos da dimensão formal da representação com que genericamente a cultura visual do mundo contemporâneo criou e produziu a imagem do Outro (seja qual for seu status: analógico, digital, eletrônico) e que será, logo após, disponibilizada, acessada e apropriada pelos usuários das redes. Essa reflexão nos conduz a pensar criticamente, no caso da disposição arquitetural de conjuntos documentais referidos ao patrimônio etnológico de Porto Alegre, o sonho de "democratização da cultura", associado às atuais redes digitais e eletrônicas, que atribui ao usuário comum das redes digitais e eletrônicas o lugar de intérprete soberano de sistemas culturais ${ }^{55}$.

\section{À guisa de conclusão}

Segundo Chartier, nas culturas contemporâneas o numérico tende a ganhar terreno como sonho do universal e com ele aposta-se no suporte eletrônico da memória como forma de circulação das informações ao considerar-se as novas redes

\footnotetext{
${ }^{52}$ Cf. R. CHARTIER, op. cit., p. 117

${ }^{53}$ Cf. CHARTIER, op. cit., p. 118

${ }^{54}$ Cf. CHARTIER, op. cit., p.117, coleções reunidas por príncipes e particulares - "imagens mutilada e decepcionante da ordem do saber"- "levou à constituição de acervos imensos, à vontade das conquistas e dos confiscos, às paixões bibliófilas e à herança de porções consideráveis do patrimônio escrito".

${ }^{55}$ Cf. P RABINOW, op. cit, p.99.
} 
eletrônicas e digitais como condição para "o progresso do espaço crítico e político que nasce do exercício público da razão por pessoas privadas" ${ }^{, 56}$.

Sob esse ponto de vista, a comunicação à distância, "livre e imediata", propiciada por redes eletrônicas, no caso de museus virtuais, recairia no tema clássico das tecnologias virtuais como lugar privilegiado no intercâmbio de julgamentos em torno das obras da cultura humana. Uma das razões que consolidam esse ponto de vista reside no fato de tais tecnologias serem vistas, desde suas origens, como máquinas e engenhos que simulam os processos e os raciocínios mentais "em tempo real" e que, sendo concebidas como projeções de processos cognitivos interiores para o exterior e tornando-os públicos, permitiram o intercâmbio de saberes e informações "justapostos ao tema da criação de identidades singulares, voltados para as diferenças". Ou seja, segue-se aqui não só o sonho da universalidade projetado pelo ideário da Modernidade onde "a afirmação das particularidades" atenderia "o desejo do universal", mas também o de que a própria imagem-interface da tela do computador represente o universal ${ }^{57}$.

Entretanto, convém que seja apontado que as novas tecnologias dos computadores, como já vimos aqui, é fruto de uma demanda de estandardização de uma cultura do consumo. Assim, the subjects have to be standardized, and the means by wich they are standardized need to be standardized as well, isto é, the private and individual is translated into public and becomes regulated ${ }^{58}$.

Dessa forma, convém que se possa refletir, no caso apresentado, sobre a especificidade da experiência de criação de um WEB site no corpo dos espaços convencionais dos museus no sentido de pontuar o lugar histórico complexo e frágil que nele ocupamos para o caso da produção de novas narrativas etnográficas, ao se incorporar, nessa apresentação, uma reflexão mais criteriosa a respeito dos constrangimentos históricos e sociais aplicados ao campo das inovações tecnológicas na área das redes digitais e eletrônicas e, no seu interior, o estudo das relações problemáticas entre imagem, subjetividade, verdade e representações.

Por um lado, parafraseando P. Rabinow ${ }^{59}$ trata-se de ver que tais inovações reafirmam a idéia de que, para o caso das modernas sociedades contemporâneas, cada

\footnotetext{
${ }^{56}$ De muitas formas, distanciamo -nos aqui da proposta de investigação de P. LEVY, As tecnologias da Inteligência. O futuro do pensamento na era da informática. Rio de Janeiro, Ed.34, 1993 e La intelligence collective. Paris. La découverte, 1997, mesmo que algumas de suas premissas sobre as relações de ordens parciais existentes entre oralidade, escrita e as novas tecnologias sejam consideradas por nós válidas.

${ }^{57}$ Cf. R. CHARTIER, op. cit., p.151

${ }^{58} \mathrm{Cf}$. L. MANOVICH, From the externalization..., op. cit., p. 1

${ }^{59}$ Cf. P RABINOW, idem, op. cit, p.100.
} 
vez mais vivemos in-between, isto é, "no meio" da reificação de identidades locais ou de construção de identidades universais. Por outro, face às nossas ilusões de um museu "extramuros", tal qual a "fantasia da biblioteca universal", não podemos ignorar que há determinadas convenções de dialogicidade/interatividade/telepresença nas redes mundiais eletrônicas e digitais, o que faz com que elas não garantam por si mesmas uma "democratização da cultura", uma vez que as novas tecnologias, como forma possível de escritura etnográfica, não "reprime o inescapável fato da textualização ${ }^{60}$.

"Situações discursivas", hipertextos multimídia, "comunidades interpretativas", telepresença, "interlocutores individuais", interatividade, “convenções e operações textuais", universalismo, são termos que podem ser empregados para o estudo dos novos suportes da memória com base nas redes eletrônicas e digitais se remetermos tais estudos a uma reflexão a respeito dos novos velhos lugares de "subjetividades interiorizadas e suas relações com normas e relações definíveis no âmbito das políticas das representações" nos termos amplamente empregados por Paul Rabinow ${ }^{61}$.

Por tudo o que vimos comentando é que se considera aqui que a pesquisa antropológica em torno de formas mais integrativas, criativas e interativas de operar e recuperar os conjuntos documentais, versando sobre o tema do patrimônio etnológico do mundo urbano contemporâneo, torna-se um espaço privilegiado de construção de novas narrativas etnográficas justamente porque através delas obtém-se uma importante chave de interpretação dos seus tempos e espaços sociais.

\footnotetext{
${ }^{60}$ Ver a respeito, P. RABINOW, op. cit., pp.85-87.

${ }^{61}$ Cf. P. RABINOW, op. cit., p. 98 .
} 


\section{BIBLIOGRAFIA}

BACHELARD, G. A dialética da duração. PUF, Paris, 1989.

BARNOW, E. El documental, historia y estilo, Barcelona, GEDISA, 1996.

BENJAMIN, W. "Walter Benjamin”. Coleção Grandes Cientistas Sociais. São Paulo, Ática, 1991. Texto 8. Pequena História da Fotografia.

CALABRESE, O. A idade Neobarroca. Lisboa, Edições 70, 1987.

CHARTIER, R. A aventura do livro, do leitor ao navegador, São Paulo, UNESP, 1999.

DORFLES, G. Elogio à Desarmonia, a Lisboa, Martins Fontes, 1986.

DURAND, G. Science de l'homme et Tradition, Paris, Berg International, 1979.

G. DURAND. G. Les structures anthropologiques de l'imaginaire, Paris, Dunod, 1984.

GIORDANIM R. De l'utilisation des témoignages oraux: aspects deontologiques. in: Etnologie Française, nouvelle série, tome 8, n 4, Paris, octobre/décembre, 1978.

JEUDY, J-P. As memórias do social. Rio de Janeiro, Forense Universtária, 1990. L.M. SCHWARCZ, O espetáculo das raças. São Paulo, Cia das Letras, 1993. LE GOFF, História e memória. Campinas, ED. UNICAMP, 1990.

LEROI-GOURHAN, Le geste et la Parole, Paris, Albin-Michel, 1964. LEVY, P. La intelligence collective. Paris. La découverte, 1997.

LEVY, P. As tecnologias da Inteligência. O futuro do pensamento na era da informática. Rio de Janeiro, Ed.34, 1993.

LINCH, K. A imagem da cidade, Lisboa, Edições 70, s.d..

MACHADO, A. Pré-cinemas \& Pós-Cinemas, São Paulo, Papirus, 1997.

MANOVICH, L. "Computer simmulation and the history of illusion". In: Digital Delirium, A Kroker e M Kroker,(Orgs), New York, St Martin’s Press, 1977.

MANOVICH, L From the externalization of Psyche to the Implantation of tecnology, In: www.apparitions.ucsd.edu/ manovich

MANOVICH, L. Computer simulation and the history of illusion, In: www.apparitions.ucsd.edu/ manovich

MANOVICH, L. “An Archeology of computer screen”, In: NewMediaTopia,, Moscow, Soros Center for Contemporary Art, 1995.

MORIN, E. Le cinéma ou l'homme imaginaire, Paris, Gonthier, 1958.

RABINOW, Antropologia da Razão, Rio de Janeiro, Relume-Dumará, 1999. RICOEUR, Tempo e Narrativa, São Paulo, Papirus, 1994.

ROCHA, A L.C da Le santuaire du désordre: l'art de savoir-vivre des tendres barbares sous les Tristes Tropiques, tese de doutorado, Paris V, Universidade René Descartes, 
Sorbonne, defendida em junho de 1994.

SIMMEL, G. Concepto de Tragedia de la Cultura y otros ensayos. Madrid, Revista de Occidente, 1935.

SUBIRATS, E. A Cultura como espetáculo,. São Paulo, Nobel 1989. VATTIMO, G. Les aventures de la différence. Paris, Editions Minuit, 1985. 